\title{
Association of lipid profile and waist circumference as cardiovascular risk factors for overweight and obesity among school children in Qatar
}

This article was published in the following Dove Press journal:

Diabetes, Metabolic Syndrome and Obesity:Targets and Therapy 19 December 2012

Number of times this article has been viewed

\section{Nasser M Rizk \\ Mervat Yousef}

Health Sciences Department, College of Arts and Sciences, Qatar University, Doha, Qatar
Correspondence: Nasser Rizk Health Sciences Department, College of Arts and Sciences, Qatar University, 27 I3 Doha, Qatar

Tel +97444034786

Fax+974 4403480 I

Email nassrizk@qu.edu.qa
Background: Childhood obesity is a national as well as worldwide problem. The aim of this study was to evaluate the association of overweight and obesity among Qatari children with lipid profile and waist circumference as adverse cardiovascular risk factors in children aged 6-11 years. International Obesity Task Force reference values were used to screen for overweight and obesity.

Methods: A cross-sectional study in a randomly selected sample was conducted in 315 Qatari primary school students aged 6-11 years. Anthropometric measurements, including body weight, height, waist circumference, and body mass index were calculated for 151 girls and 164 boys. Weight categories were based on International Obesity Task Force reference values. Fasting blood glucose, total cholesterol, high-density lipoprotein cholesterol (HDL-C), low-density lipoprotein cholesterol (LDL-C), and triglycerides were measured, and atherogenic index was calculated.

Results: In total, $31.71 \%$ of boys and $32.78 \%$ of girls were overweight or obese. Overweight and obese children screened against International Obesity Task Force reference values had a significantly increased risk of high waist circumference $(P<0.0001)$, hypertriglyceridemia $(P=0.002)$, low HDL-C $(P=0.017)$, and atherogenic index $(P=0.021)$ compared with children who were not overweight or obese. The partial correlation coefficient for the cardiovascular risk marker of waist circumference indicated a positive significant association with total cholesterol $(\mathrm{r}=0.465, P=0.003)$, triglycerides $(\mathrm{r}=0.563, P<0.001)$, and LDL-C $(\mathrm{r}=0.267, P=0.003)$, and a significant negative association with HDL-C $(\mathrm{r}=-0.361, P=0.004)$. Overweight and obesity significantly increase the odds ratios (ORs) and 95\% confidence interval (CIs) of cardiovascular risk factors as follows: hypertriglyceridemia (OR 6.34, CI 2.49-13.44, $P<0.0001$ ); LDL-C (OR 3.18, CI 1.04-9.75, $P=0.043$ ); hypercholesterolemia (OR 1.88, CI 1.10-3.19, $P=0.020$ ); and increased waist circumference (OR 1.40, CI 1.29-1.55, $P=0.022$ ). Overweight and obesity significantly increased the risk of atherosclerosis (assessed by atherogenic index) by about two-fold (OR 1.83, 95\% CI 1.06-3.15, $P=0.025$ ).

Conclusion: Overweight and obese children screened by International Obesity Task Force reference values are at increased risk of cardiovascular disease in adulthood.

Keywords: cardiovascular risks, children, lipid profile, obesity, and waist circumference

\section{Introduction}

Childhood obesity is a public health problem worldwide. ${ }^{1,2}$ Epidemiological and clinical investigations have revealed that the association between obesity and cardiovascular risk factors begins early in life. ${ }^{3,4}$ Several cross-sectional studies have shown associations between measurements of childhood adiposity, most commonly body mass index, and cardiovascular risk. ${ }^{5,6}$ Abdominal obesity as measured by 
waist circumference is associated with a significant risk of incident cardiovascular events in children. ${ }^{7}$ The pathogenesis of arteriosclerosis, which begins in childhood, is related to total cholesterol levels, with increased low-density lipoprotein cholesterol (LDL-C) and decreased high-density lipoprotein cholesterol (HDL-C) levels being independent risk factors for cardiovascular disease ${ }^{8-10}$ Childhood obesity has been associated with an abnormal lipid profile similar to that observed in adults, which could contribute to further cardiovascular risk. ${ }^{11}$ Identifying and controlling childhood obesity is an important goal in the prevention of cardiovascular disease in adulthood. ${ }^{12}$

The state of Qatar is a small country in the Arab Gulf area. Lifestyle habits there have now changed towards those of the Western world. Risk factors for childhood overweight and obesity among the young generations in Qatar are similar to those in other parts of the world. To date, there are currently no data evaluating cardiovascular risk in terms of associations of overweight and obesity with the lipid profile and intra-abdominal fat assessed by waist circumference among Qatari schoolchildren. Several recent studies have addressed the prevalence of pediatric obesity in Qatar without addressing its association with important health issues, such as development of cardiovascular disease in adulthood. ${ }^{13-15}$ This study extends our recent work, which has demonstrated a significant prevalence of metabolic syndrome and its associated features among overweight and obese children. ${ }^{16}$ The purpose of this study was to evaluate cardiovascular risk factors in overweight and obese Qatari children using International Obesity Task Force (IOTF) reference values as a screening tool. In this research, we studied the association of overweight and obesity with lipid profile and waist circumference as adverse cardiovascular risk factors in Qatari children aged 6-11 years.

\section{Materials and methods}

\section{Subjects and sample size}

A cross-sectional study was conducted in a randomly selected sample of schoolchildren in Doha, Qatar, from February to June 2005. The state of Qatar is a mainly urban area, with a land area of $11,493 \mathrm{~km}^{2}$ and an estimated population of 744,029 in $2004 .^{17}$ It is estimated that $30 \%$ of residents are nationals.

Qatari children attending primary school were selected for this study. The Qatar Ministry of Education estimated that 30,007 Qatari children were attending primary public schools (aged 6-12 years) in 2005-2006, of whom 151 girls and 164 boys were randomly selected from six local schools.
A total of 315 children were enrolled in the study, representing nearly 1\% of Qatari students enrolled in primary schools. To construct our sampling frame, schools were sampled from the Doha region using previously published information from the Ministry of Education. ${ }^{13,15}$ Only three of the six public primary schools randomly selected from the list of primary public schools consented to participate in the study. These three schools were located in the urban area of Doha government, and the children studied reflected its different socioeconomic levels. The difference in socioeconomic status was defined from household income, living conditions, and number of people per household. The samples were selected from three different geographic areas in Doha to obtain an ethnically, racially, and socioeconomically diverse sample (sample selection is critical because these factors can affect children characteristics). All children aged 6-11 years registered at each school were selected for the study. Two classes were randomly designated from each grade in every participating school. For each class, a list of student names was obtained and was arranged in alphabetical order. For each student on the list, a number was given. This was followed by random assortment of the anticipated number of students from each grade. Each student had the same chance of being entered into the study.

Healthy children were included provided that they were not suffering from diabetes, hypertension, or heart disease and were not taking any medication altering glucose and lipid levels. Children were excluded if they reported having had or having been diagnosed with acute illness, if they had undergone recent surgery or hospitalization, or if they used tobacco. Informed consent and child assent forms were completed at least 2 weeks prior to data and blood collection. The self-administered parental questionnaire provided information regarding the child's socioeconomic status and health history. Approval to conduct this study was gained by the Department of Health Sciences, Qatar University, and the Supreme Council of Education and Culture of Qatar in accordance with the ethical standards laid down by the Declaration of Helsinki (2000).

\section{Data collection and anthropometric measurements}

Age and gender data for each subject were obtained from school records. Body mass index was calculated as previously published. ${ }^{16}$ In brief, body weight was measured using a Seca scale with precision to $0.1 \mathrm{~kg}$ following a standardized procedure (lightly dressed, without shoes). Height was measured to the nearest $0.1 \mathrm{~cm}$ using a stadiometer, with the shoulders 
in a relaxed position. Body mass index was calculated by dividing weight $(\mathrm{kg})$ by height $\left(\mathrm{m}^{2}\right)$. Waist circumference was measured in duplicate with the subjects standing dressed in light clothes. Waist circumference was measured using a flexible non-elastic tape with subjects standing at the smallest abdominal position between the iliac crest and the lower rib margin at the end of normal expiration. The measurements were recorded to the nearest $0.5 \mathrm{~cm}$. Maintaining the Frankfort plane ensured correct posture of the subject. A physician and trained nurses conducted the anthropometric, clinical examination, and blood withdrawal in the school clinic.

\section{Biochemical parameters}

A morning venous blood sample after an overnight fast (10-12 hours) was drawn at each clinic unit in schools. Fasting blood glucose, total cholesterol, triglycerides, highdensity lipoprotein cholesterol (HDL-C), and low-density lipoprotein cholesterol (LDL-C) were determined as previously published. ${ }^{18}$ Atherogenic index (AI) was calculated by the equation:

$$
\mathrm{AI}=[(\text { total cholesterol }-\mathrm{HDL}-\mathrm{C}) / \mathrm{HDL}-\mathrm{C}]{ }^{19}
$$

\section{Cutoff values}

IOTF reference values were adopted for classification of children as overweight or obese. ${ }^{20}$ The IOTF cutoff values are obtained by extrapolating from body mass index percentiles corresponding to $>25$ (overweight) and $>30 \mathrm{~kg} / \mathrm{m}^{2}$ (obese) at age 18 years. ${ }^{20}$ Abdominal obesity was defined as having a waist circumference $\geq 90$ th percentile for age and gender. ${ }^{21}$ The cutoff values from the National Cholesterol Education Program lipid assessments for children were adopted. ${ }^{22}$ Abnormalities in lipid levels have traditionally been defined as concentrations $\geq 95$ th percentile for total cholesterol, triglycerides, and LDL-C for age and gender, whereas low HDL-C concentrations have traditionally been defined as $<5$ th percentile for age and gender. Undesirable abnormal levels were $\geq 5.2 \mathrm{mM}$ for total cholesterol, $\geq 3.4 \mathrm{mM}$ for LDL-C, $<0.9 \mathrm{mM}$ for HDL-C, and $\geq 1.24 \mathrm{mM}$ for triglycerides. ${ }^{22}$ The cutoff value for fasting blood glucose was $\geq 5.6 \mathrm{mM}$ according to recommendations by the American Diabetes Association. ${ }^{23}$

\section{Statistical analysis}

Statistical evaluation was performed using the Statistical Package for the Social Sciences software version 19 for Windows (SPSS Inc, Chicago, IL). All data were expressed as the mean \pm standard deviation unless stated otherwise. Data were explored for outliers, skewness, and normality.
Mean values and prevalence of cardiovascular risk factors were compared between children who were not overweight or obese and children who were overweight and obese in separate linear or logistic models, with individual cardiovascular risk factors as dependent variables, and overweight and obesity status as a dichotomous explicative variable, adjusted for gender and age. Chi-square testing was used to assess for differences between categorical variables. Partial Pearson correlations, adjusted for age, gender, and body mass index, were calculated for waist circumference and metabolic risk factors. Logistic regression analysis was used to estimate the odds ratios (ORs) for the studied adverse cardiovascular risk factors for overweight and obese children referenced to children who were not overweight or obese. A two-sided $P<0.05$ was considered to be statistically significant.

\section{Results}

\section{Characteristics of study participants}

The sample included 151 girls (47.9\%) and 164 boys (52.1\%). Table 1 shows the mean values and standard deviations for the anthropometric and biochemical characteristics of the study subjects by gender and age.

\section{Prevalence of overweight and obesity by IOTF reference values}

Figure 1 shows the overall frequencies of weight status using IOTF categories by gender. The prevalence of obesity was $21.95 \%$ in boys and $16.56 \%$ in girls, whereas the prevalence of overweight was $9.76 \%$ and $17.22 \%$ in boys and girls, respectively. Using Chi-square testing, no significant difference was observed between the prevalence of obesity in boys $(P=0.706)$ and that in girls $(P=0.656)$ using IOTF reference values.

\section{Anthropometric and biochemical variables by IOTF values based on overweight and obesity}

Using the IOTF criteria, mean waist circumference was significantly higher in overweight and obese children than in children who were not overweight or obese $(P<0.0001)$, as shown in Table 2. Mean serum triglyceride levels were significantly higher in overweight and obese children than in those who were not overweight or obese $(P=0.002)$, while HDL-C was significantly lower in overweight or obese children than in children who were not overweight and obese $(P=0.017)$. No significant differences were detected in serum glucose, total 
Table I Descriptive characteristics of a sample of Qatari schoolchildren by age and gender

\begin{tabular}{|c|c|c|c|c|c|c|c|}
\hline & Gender & 6 years & 7 years & 8 years & 9 years & 10 years & II years \\
\hline \multirow[t]{2}{*}{ Subjects (n) } & $M(n=164)$ & 12 & 38 & 23 & 33 & 34 & 24 \\
\hline & $F(n=151)$ & 15 & 32 & 24 & 28 & 25 & 27 \\
\hline \multirow[t]{2}{*}{ Weight (kg) } & M & 25.29 & 24.53 & 28.53 & 35.32 & 36.83 & 43.31 \\
\hline & $\mathrm{F}$ & 21.67 & 25.88 & 27.92 & 32.16 & 38.00 & 42.17 \\
\hline \multirow[t]{2}{*}{ Height (cm) } & $M$ & 120.56 & 121.86 & 128.69 & 133.15 & 137.65 & 142.18 \\
\hline & $\mathrm{F}$ & 119.09 & 122.84 & 128.18 & 131.29 & 137.68 & 145.28 \\
\hline \multirow[t]{2}{*}{ BMI $\left(\mathrm{kg} / \mathrm{m}^{2}\right)$} & $M$ & 17.17 & 16.34 & 17.06 & 19.52 & 19.15 & 21.07 \\
\hline & $\mathrm{F}$ & 15.01 & 17.03 & 16.79 & 18.44 & 19.80 & 19.87 \\
\hline \multirow[t]{2}{*}{ Waist circumference $(\mathrm{cm})$} & $M$ & 55.32 & 55.97 & 57.63 & 62.88 & 63.76 & 67.06 \\
\hline & $\mathrm{F}$ & $50.4 I$ & 56.81 & 58.23 & 60.47 & 61.35 & 65.49 \\
\hline \multirow[t]{2}{*}{ Glucose (mM) } & $M$ & 5.18 & 5.29 & 5.27 & 5.40 & 5.37 & 5.32 \\
\hline & $\mathrm{F}$ & 5.45 & 5.26 & 5.21 & 5.35 & 5.24 & 5.46 \\
\hline \multirow[t]{2}{*}{$\mathrm{TC}(\mathrm{mM})$} & $M$ & 3.92 & 4.44 & 4.70 & 4.35 & 4.58 & 4.82 \\
\hline & $\mathrm{F}$ & 5.32 & 4.87 & 4.85 & 4.96 & 4.59 & 4.81 \\
\hline \multirow[t]{2}{*}{ TG (mM) } & $M$ & 0.62 & 0.63 & 0.69 & 0.74 & 0.79 & 0.96 \\
\hline & $\mathrm{F}$ & 0.85 & 1.03 & 0.92 & 0.96 & 1.07 & 1.15 \\
\hline \multirow[t]{2}{*}{ HDL-C (mM) } & M & 1.34 & 1.46 & 1.73 & 1.46 & 1.54 & 1.34 \\
\hline & $\mathrm{F}$ & 1.55 & 1.24 & 1.34 & 1.29 & 1.21 & 1.26 \\
\hline \multirow[t]{2}{*}{ LDL-C (mM) } & $M$ & 2.27 & 2.68 & 2.54 & 2.54 & 2.59 & 3.04 \\
\hline & $\mathrm{F}$ & 3.40 & 3.17 & 3.10 & 3.18 & 2.91 & 2.92 \\
\hline
\end{tabular}

Note: Data are presented as mean values.

Abbreviations: M, boys; F, girls; WC, waist circumference; TC, total cholesterol; TG, triglycerides; HDL-C, high-density lipoprotein cholesterol; LDL-C, low-density lipoprotein cholesterol; BMI, body mass index.

cholesterol, or LDL-C between overweight and obese children and those who were not overweight or obese (Table 2).

\section{Numbers of children at high}

\section{cardiovascular risk}

Table 3 shows the number of children at abnormal cardiovascular risk. Overweight and obese children had significantly higher percentages of the following adverse cardiovascular risk factors: hypercholesterolemia $(P<0.0001)$, hypertriglyceridemia $(P<0.0001)$, increased waist circumference $(P<0.0001)$,

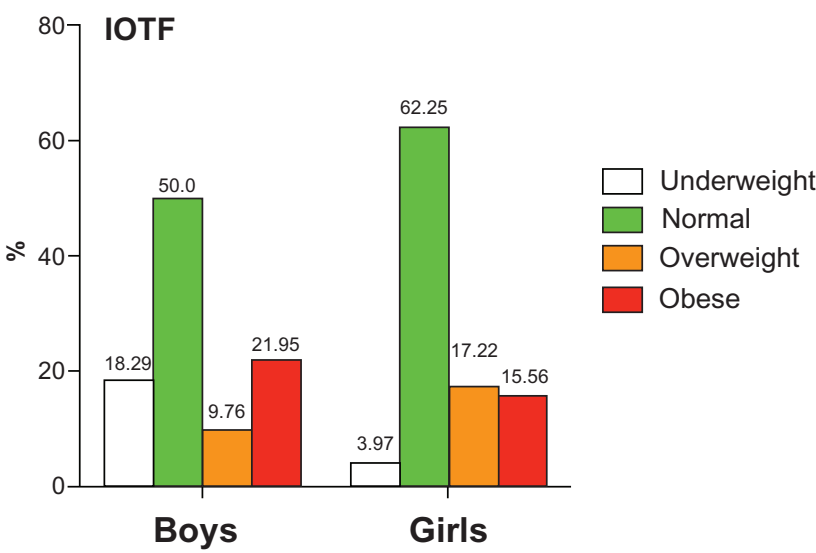

Figure I Frequencies of obesity, overweight, normal weight, and thinness by gender in boys and girls aged 6-1I years, assessed by IOTF reference values.

Notes: Cutoff values are given in the Materials and methods section.

Abbreviation: IOTF, International Obesity Task Force. increased atherogenic index $(P=0.028)$, and decreased HDL-C $(P=0.037)$. No significant difference was detected for increased LDL-C and hyperglycemia.

\section{Correlation between cardiovascular risk and lipid variables}

Bivariate partial correlations between waist circumference and biochemical markers for cardiovascular risk after

Table 2 Characteristics of the 315 participants according to absence or presence of overweight and obesity using IOTF criteria

\begin{tabular}{lccl}
\hline Variables & $\begin{array}{l}\text { Not overweight } \\
\text { or obese }\end{array}$ & $\begin{array}{l}\text { Overweight } \\
\text { and obese }\end{array}$ & P value \\
\hline Age $($ years $)$ & $8.63 \pm 1.5 \mathrm{I}$ & $8.95 \pm 1.4 \mathrm{I}$ & 0.073 \\
Weight $(\mathrm{kg})$ & $26.9 \mathrm{I} \pm 7.84$ & $45.1 \mathrm{I} \pm 10.95^{*}$ & $<0.000 \mathrm{I}$ \\
Height $(\mathrm{cm})$ & $129.44 \pm 9.44$ & $136.10 \pm 8.66^{*}$ & 0.012 \\
BMI $\left(\mathrm{kg} / \mathrm{m}^{2}\right)$ & $15.86 \pm 2.66$ & $23.93 \pm 3.76^{*}$ & $<0.000 \mathrm{I}$ \\
WC $(\mathrm{cm})$ & $55.48 \pm 0.46$ & $72.26 \pm 0.68^{*}$ & $<0.000 \mathrm{I}$ \\
Glucose $(\mathrm{mM})$ & $5.29 \pm 0.0 .03$ & $5.38 \pm 0.04$ & $0.27 \mathrm{I}$ \\
TC $(\mathrm{mM})$ & $4.62 \pm 0.06$ & $4.76 \pm 0.09$ & 0.094 \\
TG $(\mathrm{mM})$ & $0.75 \pm 0.03$ & $1.13 \pm 0.04^{*}$ & 0.002 \\
HDL-C (mM) & $1.44 \pm 0.02$ & $1.31 \pm 0.04^{*}$ & 0.017 \\
LDL-C $(\mathrm{mM})$ & $2.77 \pm 0.05$ & $2.89 \pm 0.07$ & 0.117 \\
Al & $2.33 \pm 0.05$ & $2.8 \mathrm{I} \pm 0.08^{*}$ & $0.02 \mathrm{I}$ \\
\hline
\end{tabular}

Notes: Data are presented as the mean \pm standard deviation. $* P<0.05$, statistically significant when compared with not overweight or obese.

Abbreviations: IOTF, International Obesity Task Force; BMl, body mass index; WC, waist circumference; TC, total cholesterol; TG, triglycerides; HDL-C, highdensity lipoprotein cholesterol; LDL-C, low-density lipoprotein cholesterol; Al, atherogenic index. 
Table 3 Numbers of children with high levels of cardiovascular risk factors among study subjects according to IOTF criteria

\begin{tabular}{llll}
\hline Variables & $\begin{array}{l}\text { Not overweight } \\
\text { or obese } \\
(\mathbf{n}=\mathbf{2} \text { I5) }\end{array}$ & $\begin{array}{l}\text { Overweight } \\
\text { and obese } \\
(\mathbf{n}=100)\end{array}$ & $\begin{array}{l}\text { P value } \\
\end{array}$ \\
\hline Hyperglycemia (\%) & $8(3.7)$ & $5(5.0)$ & 0.559 \\
Increased WC (\%) & $2(0.9)$ & $38(38.0)^{*}$ & $<0.000$ I \\
Hypertriglyceridemia (\%) & $10(4.7)$ & $25(25.0)^{*}$ & $<0.000$ I \\
Hypercholesterolemia (\%) & $33(24.2)$ & $52(52.0)^{*}$ & $<0.000$ I \\
Low HDL-C (\%) & $6(0.8)$ & $12(12.0)^{*}$ & 0.037 \\
High LDL-C (\%) & $47(21.9)$ & $28(28.0)$ & 0.124 \\
High Al & $95(44.2)$ & $77(77.0)^{*}$ & 0.028 \\
\hline
\end{tabular}

Notes: Values are expressed as the number and the percentage between brackets. $* P<0.05$, statistically significant when compared with children who are not overweight or obese as controls.

Abbreviations: WC, waist circumference; TC, total cholesterol; TG, triglycerides; HDL-C, high-density lipoprotein cholesterol; LDL-C, low-density lipoprotein cholesterol; Al, atherogenic index; IOTF, International Obesity Task Force.

adjustment for age and gender are summarized in Table 4 . Circulating total cholesterol $(\mathrm{r}=0.465, P=0.003)$, triglycerides $(\mathrm{r}=0.563, P<0.001)$, and LDL-C $(\mathrm{r}=0.267, P=0.003)$ showed a significant positive correlation with waist circumference, but HDL-C showed a significant negative correlation with waist circumference $(\mathrm{r}=-0.361, P=0.004)$.

We calculated ORs and 95\% confidence interval (CIs) using logistic regression analysis (Figure 2) between overweight and obesity as an independent variable and the study cardiovascular risk factors for all subjects as independent variables, ie, hyperglycemia, hypercholesterolemia, hypertriglyceridemia, increased LDL-C, increased waist circumference, increased atherogenic index, and decreased HDL-C. Overweight and obese children were 1.88 times more likely to have a high total cholesterol level $(P=0.020), 6.34$ times more likely to have high triglyceride levels $(P<0.000)$, 1.97 times more likely to have a high atherogenic index $(P=0.019), 1.40$ times more likely to have a waist circumference above the 90 th percentile $(P=0.022)$, and 1.88 times

Table 4 Partial correlation coefficient for waist circumference as a cardiovascular risk marker in 315 children

\begin{tabular}{lll}
\hline Cardiovascular risk marker & Correlation coefficient & $\boldsymbol{P}$ value \\
\hline TC & 0.465 & 0.003 \\
HDL-C & -0.361 & 0.004 \\
LDL-C & 0.267 & 0.003 \\
TG & 0.563 & $<0.001$ \\
Glucose & 0.086 & 0.129 \\
\hline
\end{tabular}

Notes: Data are given in $r$ and $P$ values. Correlation coefficient was assessed by partial correlation method adjusted for age, gender, and body mass index. $P<0.05$ is significant.

Abbreviations: TG, triglycerides; HDL-C, high-density lipoprotein cholesterol; LDL-C, low-density lipoprotein cholesterol; TC, total cholesterol.

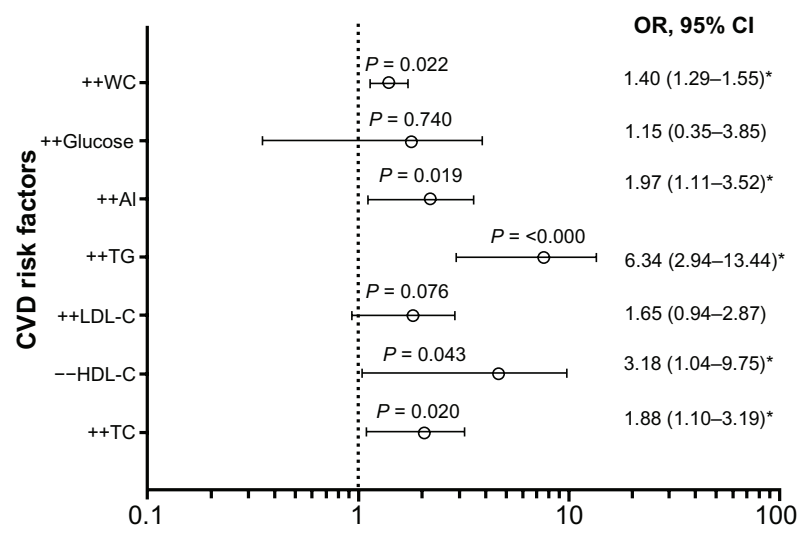

Figure 2 Odds ratios and $95 \%$ confidence intervals in overweight or obese children as the dependent variable, and WC, glucose, Al, TC, HDL, LDL, and TG as the independent variables in all study school children aged 6-II years compared with children who were not overweight or obese as controls, assessed by IOTF reference values.

Notes: ++, increased or high; --, decreased or low. Two-tailed $* P<0.05$ is statistically significant when compared with children who were not overweight or obese as controls assessed by logistic regression analysis.

Abbreviations: CVD, cardiovascular disease; WC, waist circumference; TC, total cholesterol; TG, triglycerides; HDL-C, high-density lipoprotein cholesterol; LDL-C, low-density lipoprotein cholesterol; Al, atherogenic index; OR, odds ratio; $\mathrm{Cl}$, confidence interval; IOTF, International Obesity Task Force.

more likely to have a low HDL-C $(P=0.043)$ in comparison with children who were not overweight or obese.

\section{Discussion}

This study evaluated the relationship of lipid profile and waist circumference as cardiovascular risk factors with overweight and obesity in Qatari children. The main findings of our study were that overweight and obese children screened by IOTF criteria had consistently more adverse cardiovascular risk factors, including increased waist circumference, hypercholesterolemia, hypertriglyceridemia, and atherogenic index, with lower levels of HDL-C than children who were not overweight or obese. In addition, overweight and obesity in children increases the odds of having cardiovascular risk factors, ie, increased waist circumference, hypercholesterolemia, and hypertriglyceridemia, with lower levels of HDL-C and atherosclerosis.

Several studies have shown that the association between obesity and cardiovascular risk begins early in life., 3 Body mass index and waist circumference each measure a distinct component of obesity or body fat distribution, and waist circumference is consistently the best predictor of cardiovascular risk. ${ }^{24,25}$ Few studies are available on the relationship between waist circumference and cardiovascular risk factors in children. ${ }^{26,27}$ The results of the current study showed significant positive correlations between waist circumference and total cholesterol, triglycerides, and LDL-C, and an inverse correlation with HDL-C after adjustment for age and gender. The findings of the current study are in agreement 
with previous studies ${ }^{11,28,29}$ demonstrating a significant association between increased waist circumference and lipid profile. Hirschler et al demonstrated a significant association $(P<0.01)$ between waist circumference and high-density lipoprotein cholesterol $(\mathrm{r}=0.45)$, triglyceride $(\mathrm{r}=0.28)$ levels in 84 students aged $6-13$ years. ${ }^{28}$ Cowin and Emmett reported that central obesity had a significant correlation with triglycerides and HDL-C levels in preschool children that was independent of height and body mass index. ${ }^{29}$ The findings of the current study also agree with the results of the Bogalusa Heart Study, which reported an inverse association between waist circumference and HDL-C in children aged 5-9 years. ${ }^{30}$

Abnormal serum lipid levels, especially decreased HDL-C and elevated total cholesterol, triglycerides, and LDL-C, are generally recognized as independent risk factors for cardiovascular disease. ${ }^{31-33}$ Our study demonstrated an abnormal lipid profile with regard to elevated total cholesterol, triglycerides, LDL-C, and atherogenic index, and reduced HDL-C in overweight or obese children. Our results show that overweight and obesity in school children increases the likelihood of adverse cardiovascular risk factors, including increased waist circumference and hypercholesterolemia, hypertriglyceridemia, and low HDL-C, which is consistent with previous studies. ${ }^{34-36}$ Botton et al showed partial correlations between hypertriglyceridemia, hyperinsulinemia, and low plasma HDL-C levels that were related to all measures of adiposity in 452 children aged 8-17 years. In addition, they demonstrated that moderate excess weight is linked with increased cardiovascular risk, and among girls, abdominal fat distribution is correlated with cardiovascular risk factors independently of adiposity markers. ${ }^{34}$ In agreement with our findings, another study performed in Venezuela in a sample of 370 second grade students aged $7.82 \pm 0.62$ years found a significant positive correlation between waist circumference, body mass index, and atherogenic indices, ie, triglycerides/ HDL-C, total cholesterol/HDL-C, and low-density lipoprotein cholesterol/HDL-C $(P=0.0001) .{ }^{36}$

The lipid profile results for children in the current study highlight the risks of dyslipidemia among Qatari school children and its consequences for the cardiovascular system. Long-term observations from the Bogalusa Heart Study demonstrate that obesity in childhood is a major driving force for insulin resistance syndrome. Recent studies have demonstrated that insulin resistance is implicated in the association between obesity and dyslipidemia, which contributes to an increased risk of cardiovascular disease. ${ }^{37}$
In addition, the current study shows a high prevalence of pediatric overweight, including obesity, in Qatari children (31.71\% in boys and 33.78.\% in girls) by IOTF criteria. The results of this study are similar to those of a recent study by Kerkadi et al, which reported a prevalence of overweight and obesity by age of $33.2 \%, 33.5 \%$, and $44.7 \%$ for boys and $37.0 \%, 38.9 \%$ and $43.3 \%$ for girls aged 9,10 , and 11 years using IOTF references, respectively. ${ }^{15}$ Other studies among adolescents in Qatar report a high risk of overweight and obesity. ${ }^{14}$ In the United Arab Emirates, it has been reported that $21.5 \%$ of children aged 5-17 years are overweight and $13.7 \%$ are obese..$^{38}$ This study indicates an apparently elevated frequency of overweight and obesity among children in the Gulf region, at rates close to that reported in the current study among children aged 6-11 years. The proportions of overweight and obesity among children in our study are similar to or higher than those reported in some industrialized countries in the past few decades. . $^{1,39,40}$

In summary, the present study indicates that the combination of elevated total cholesterol, triglycerides, and LDL-C, and decreased HDL-C, with waist circumference above the 90th percentile in overweight and obese children, would place them at greater risk for cardiovascular disease. These data are consistent with previous studies in different ethnic groups. ${ }^{41,42}$ Further studies are needed in larger sample sizes to investigate if other biomarkers could be used to define obesity and overweight among Qatari schoolchildren and the implications for early detection of increased cardiovascular risk.

The present study was limited by its small size sample of 300,000 Qatari schoolchildren. Blood pressure was not measured, which limits the associations of obesity with the metabolic syndrome as a cluster of potential risk factors for atherosclerotic cardiovascular disease and type 2 diabetes. Further pubertal stage was not determined in this crosssectional study, which prevents measurement of lipid profile at different stages of puberty.

\section{Conclusion}

Overweight and obese Qatari children screened by IOTF criteria have increased cardiovascular risk factors related to triglycerides, total cholesterol, low-HDL, atherogenic index, and waist circumference. This finding has significant public health implications in Qatar, given the associations between obesity, waist circumference, metabolic abnormalities of the lipid profile, and cardiovascular risk in adult life. This suggests that control of excessive weight gain in children is likely to have long-term benefits. 


\section{Acknowledgment}

This study was funded by a grant from the College of Arts and Sciences, Qatar University (CAS05001), and would not have been possible without the students, physicians, and nurses who helped in data collection.

\section{Disclosure}

The authors report no conflicts of interest in this work.

\section{References}

1. Lobstein T, Baur L, Uauy R. Obesity in children and young people: a crisis in public health. Obes Rev. 2004;5 Suppl 1:4-104.

2. de Onis M, Blossner M. Prevalence and trends of overweight among preschool children in developing countries. Am J Clin Nutr. 2000;72 1032-1039.

3. Short KR, Blackett PR, Gardner AW, Copeland KC. Vascular health in children and adolescents: effects of obesity and diabetes. Vasc Health Risk Manag. 2009;5:973-990.

4. Bridger T. Childhood obesity and cardiovascular disease. Paediatr Child Health. 2009;14:177-182.

5. Must A, Strauss RS. Risks and consequences of childhood and adolescent obesity. Int J Obes Relat Metab Disord. 1999;23 Suppl 2: S2-S11.

6. Ice CL, Cottrell L, Neal WA. Body mass index as a surrogate measure of cardiovascular risk factor clustering in fifth-grade children: results from the coronary artery risk detection in the Appalachian Communities Project. Int J Pediatr Obes. 2009;4:316-324.

7. Jung C, Fischer N, Fritzenwanger M, Pernow J, Brehm BR, Figulla HR. Association of waist circumference, traditional cardiovascular risk factors, and stromal-derived factor-1 in adolescents. Pediatr Diabetes. 2009;10:329-335.

8. Sanchez-Bayle M, Gonzalez-Requejo A, Ruiz-Jarabo C, et al. Serum lipids and apolipoproteins in Spanish children and adolescents: a 5 year follow-up. Acta Paediatr. 1996;85:292-294.

9. Berenson GS, Wattigney WA, Tracy RE, et al. Atherosclerosis of the aorta and coronary arteries and cardiovascular risk factors in persons aged 6 to 30 years and studied at necropsy (The Bogalusa Heart Study). Am J Cardiol. 1992;70:851-858.

10. Voller H, Schmailzl KJ, Bjarnason-Wehrens B. Obesity and cardiovascular diseases-theoretical background and therapeutic consequences. Zeitschrift fur Kardiologie. 2004;93:503-513. German.

11. Falaschetti E, Hingorani AD, Jones A, et al. Adiposity and cardiovascular risk factors in a large contemporary population of pre-pubertal children. Eur Heart J. 2010;31:3063-3072.

12. Whitaker RC, Wright JA, Pepe MS, Seidel KD, Dietz WH. Predicting obesity in young adulthood from childhood and parental obesity. N Engl J Med. 1997;337:869-873.

13. Bener A. Prevalence of obesity, overweight, and underweight in Qatari adolescents. Food Nutr Bull. 2006;27:39-45.

14. Qotba H, Al-Isa AN. Anthropometric measurements and dietary habits of schoolchildren in Qatar. Int J Food Sci Nutr. 2007;58:1-5.

15. Kerkadi A, Abdelmonem HS, Adil Eltayeb YM. High prevalence of the risk of overweight and overweight among Qatari children ages 9 through 11. Nutr Food Sci. 2009;39:36-45.

16. Rizk N, Amin M, Yousef M. A pilot study on metabolic syndrome and its associated features among Qatari schoolchildren. Int J Gen Med. 2011;4:521-525.

17. Qatar Embassy. Available from: http://qatarembassy.net/population. asp. Accessed November 6, 2012.

18. El-Menyar A, Rizk N, Al Nabti AD, et al. Total and high molecular weight adiponectin in patients with coronary artery disease. J Cardiovasc Med (Hagerstown). 2009;10:310-315.
19. Schulpis K, Karikas GA. Serum cholesterol and triglyceride distribution in 7767 school-aged Greek children. Pediatrics. 1998;101:861-864.

20. Cole TJ, Bellizzi MC, Flegal KM, Dietz WH. Establishing a standard definition for child overweight and obesity worldwide: international survey. BMJ. 2000;320:1240-1243.

21. Knerr I. Obesity and the metabolic syndrome in children and adolescents. MMW Fortschr Med. 2004;146:41-43.

22. National Cholesterol Education Program. Highlights of the report of the expert panel on blood cholesterol levels in children and adolescents. Pediatrics. 1992;89:495-501.

23. Genuth $\mathrm{S}$, Alberti KG, Bennett $\mathrm{P}$, et al. Follow-up report on the diagnosis of diabetes mellitus. Diabetes Care. 2003;26:3160-3167.

24. Hirschler V, Molinari C, Maccallini G, Aranda C, Oestreicher K. Comparison of different anthropometric indices for identifying dyslipidemia in school children. Clin Biochem. 2011;44:659-664.

25. Bitsori M, Linardakis M, Tabakaki M, Kafatos A. Waist circumference as a screening tool for the identification of adolescents with the metabolic syndrome phenotype. Int J Pediatr Obes. 2009;4: 325-331.

26. Savva SC, Tornaritis M, Savva ME, et al. Waist circumference and waist-to-height ratio are better predictors of cardiovascular disease risk factors in children than body mass index. Int J Obes Relat Metab Disord. 2000;24:1453-1458.

27. Maffeis C, Pietrobelli A, Grezzani A, Provera S, Tato L. Waist circumference and cardiovascular risk factors in prepubertal children. Obes Res. 2001;9:179-187.

28. Hirschler V, Aranda C, Calcagno Mde L, Maccalini G, Jadzinsky M. Can waist circumference identify children with the metabolic syndrome? Arch Pediatr Adolesc Med. 2005;159:740-744.

29. Cowin I, Emmett P. Cholesterol and triglyceride concentrations, birthweight and central obesity in pre-school children. ALSPAC Study Team. Avon Longitudinal Study of Pregnancy and Childhood. Int J Obes Relat Metab Disord. 2000;24:330-339.

30. Freedman DS, Kahn HS, Mei Z, et al. Relation of body mass index and waist-to-height ratio to cardiovascular disease risk factors in children and adolescents: the Bogalusa Heart Study. Am J Clin Nutr. 2007;86:33-40.

31. Pascot A, Lemieux I, Bergeron J, et al. HDL particle size: a marker of the gender difference in the metabolic risk profile. Atherosclerosis. 2002;160:399-406.

32. Manios Y, Dimitriou M, Moschonis G, et al. Cardiovascular disease risk factors among children of different socioeconomic status in Istanbul, Turkey: directions for public health and nutrition policy. Lipids Health Dis. 2004;3:11.

33. Garcia RE, Moodie DS. Implications of childhood hypercholesterolemia. Cleve Clin J Med. 1990;57:715-720.

34. Botton J, Heude B, Kettaneh A, et al. Cardiovascular risk factor levels and their relationships with overweight and fat distribution in children: the Fleurbaix Laventie Ville Sante II study. Metabolism. 2007;56: 614-622.

35. Glowinska B, Urban M, Koput A. Cardiovascular risk factors in children with obesity, hypertension and diabetes: lipoprotein(a) levels and body mass index correlate with family history of cardiovascular disease. Eur J Pediatr. 2002;161:511-518.

36. Paoli M, Uzcategui L, Zerpa Y, et al. Obesity in schoolchildren from Merida, Venezuela: association with cardiovascular risk factors. Endocrinol Nutr. 2009;56:218-226. Spanish.

37. Kurtoglu S, Hatipoglu N, Mazicioglu M, Kendirici M, Keskin M, Kondolot M. Insulin resistance in obese children and adolescents: HOMA-IR cut-off levels in the prepubertal and pubertal periods. J Clin Res Pediatr Endocrinol. 2010;2:100-106.

38. Malik M, Bakir A. Prevalence of overweight and obesity among children in the United Arab Emirates. Obes Rev. 2007;8:15-20.

39. Kelishadi R. Childhood overweight, obesity, and the metabolic syndrome in developing countries. Epidemiol Rev. 2007;29: $62-76$. 
40. Tremblay MS, Katzmarzyk PT, Willms JD. Temporal trends in overweight and obesity in Canada, 1981-1996. Int J Obes Relat Metab Disord. 2002;26:538-543.

41. Chu NF, Rimm EB, Wang DJ, Liou HS, Shieh SM. Clustering of cardiovascular disease risk factors among obese schoolchildren: the Taipei Children Heart Study. Am J Clin Nutr. 1998;67:1141-1146.
42. Toledo-Corral CM, Ventura EE, Hodis HN, et al. Persistence of the metabolic syndrome and its influence on carotid artery intima media thickness in overweight Latino children. Atherosclerosis. 2009;206: 594-598.

\section{Publish your work in this journal}

Diabetes, Metabolic Syndrome and Obesity: Targets and Therapy is an international, peer-reviewed open-access journal committed to the rapid publication of the latest laboratory and clinical findings in the fields of diabetes, metabolic syndrome and obesity research. Original research, review, case reports, hypothesis formation, expert opinion and commentaries are all considered for publication. The manuscript management system is completely online and includes a very quick and fair peer-review system, which is all easy to use. Visit http://www.dovepress.com/testimonials.php to read real quotes from published authors. 